\title{
Solusi Persamaan Klein-Gordon Nonlinear untuk Partikel Bebas
}

\author{
T. B. Prayitno* \\ Kelompok Fisika Teoretik, Departemen Fisika Universitas Negeri Jakarta \\ Jl. Pemuda Rawamangun No. 10
}

\begin{abstract}
Intisari
Pada makalah ini telah dikaji persamaan Klein-Gordon nonlinear yang dirumuskan melalui dua persamaan hukum kekekalan energi klasik, yaitu persamaan Hamilton-Jacobi dan kontinuitas. Secara umum, persamaan ini diturunkan melalui analogi yang sama pada penurunan persamaan nonlinear Schrodinger yang tidak menggunakan dua postulat di dalam mekanika kuantum, yaitu postulat Einstein dan de Broglie mengenai kuantisasi energi dan momentum linear. Asumsi yang digunakan pada penurunan persamaan tersebut adalah mengambil postulat bahwa persamaan Hamilton-Jacobi tetap berlaku dalam sistem mikroskopik. Solusi partikel bebas untuk persamaan Klein-Gordon nonlinear ini mempunyai solusi khusus berupa solusi gelombang bidang monokromatik. Di samping itu, telah di bahas pula bentuk umum persamaan Klein-Gordon nonlinear yang memasukkan unsur potensial eksternal.
\end{abstract}

KATA KUNCI: Klein-Gordon nonlinear

\section{PENDAHULUAN}

Teori mekanika kuantum dirumuskan untuk mempelajari sistem mikroskopik yang mempunyai dua aspek penting yang ditunjukkan melalui hasil eksperimen (salah satu contoh eksperimen yang pernah dilakukan adalah difraksi neutron). Kedua aspek tersebut adalah aspek partikel dan gelombang, namun kedua aspek tersebut tidak pernah muncul secara bersamaan. Kemunculan kedua aspek di dalam hasil eksperimen tersebut tidak dapat dijelaskan oleh fisika klasik yang telah diterima kurang lebih selama tiga abad lamanya. Pada awal lahirnya teori mekanika kuantum, Heisenberg dan Schrodinger telah mengajukan persamaannya masing-masing untuk menjelaskan fenomena hasil persamaan. Heisenberg mengajukan teori mekanika matriks yang mendeskripsikan karakteristik partikel sedangkan Schrodinger mengajukan teori mekanika gelombang yang menggambarkan perilaku gelombang. Kedua persamaan tersebut sampai sekarang dapat digunakan untuk mempelajari sistem mikroskopik. Di sisi lain, Einstein dan de Broglie yang merupakan dua tokoh pencetus teori mekanika kuantum melalui postulat kuantisasi energi dan momentum linear meyakini bahwa mekanika kuantum yang paling fundamental adalah mekanika kuantum nonlinear. Hal ini membuat beberapa fisikawan tertarik untuk merumuskan mekanika kuantum nonlinear tersebut.

Perumusan mekanika kuantum nonlinear tersebut pertama kali diajukan oleh fisikawan asal Italia, Guerra, Pusterla, dan Smolin yang mengajukan persamaan Schrodinger nonlinear [1-4]. Pembahasan mendalam mengenai persamaan Schrodinger nonlinear beserta karakteristiknya telah dibahas pada referensi [1-4]. Persamaan ini diturunkan berdasarkan

\footnotetext{
${ }^{*}$ E-MAIL: trunk_002@yahoo.com
}

adanya postulat keberlakuan persamaan kekekalan energi klasik, yaitu persamaan Hamilton-Jacobi dan kontinuitas pada sistem mikroskopik. Di samping itu, persamaan ini memunculkan sebuah potensial kuantum yang pada hakikatnya adalah suku nonlinear yang ditambahkan pada persamaan Schrodinger linear. Dengan demikian, penurunan persamaan ini tidak menggunakan prinsip kuantisasi energi dan momentum linear yang telah diajukan oleh Einstein dan de Broglie. Dengan adanya postulat keberlakuan persamaan energi klasik tersebut, partikel kuantum dapat dianggap mempunyai bagian partikel yang direpresentasikan oleh persamaan Hamilton-Jacobi dan bagian gelombang yang digambarkan melalui persamaan kontinuitas. Menurut ketiga fisikawan tersebut, bagian partikel mempunyai sebagian besar energi partikel kuantum dan bertanggung jawab pada terdeteksinya suatu partikel pada suatu detektor sedangkan bagian gelombang mempunyai sebagian kecil energi partikel kuantum dan bertanggung jawab terhadap terjadinya pola-pola interferensidifraksi. Melalui tafsiran ini, partikel kuantum dapat digambarkan seperti pusaran angin, dengan bagian partikel terletak pada pusat pusaran sedangkan bagian gelombang berputar mengelilingi bagian partikel.

Tujuan dari makalah ini adalah merumuskan persamaan Klein-Gordon nonlinear berdasarkan konsep yang sama pada penurunan persamaan Schrodinger linear di atas. Sebagai permulaan, akan dibahas mengenai motivasi dapat dirumuskannya persamaan tersebut, lalu dilanjutkan dengan perumusan persamaan Klein-Gordon untuk partikel bebas. Selain itu, solusi khusus partikel bebas untuk persamaan ini berbentuk gelombang bidang monokromatik yang mempunyai sifat yang mirip pada solusi persamaan Klein-Gordon linear yang secara umum mempunyai dua solusi energi, yaitu energi positif dan negatif. Akhir dari makalah ini akan dirumuskan persamaan Klein-Gordon umum yang memasukkan unsur potensial eksternal. 


\section{MOTIVASI PENURUNAN PERSAMAAN KLEIN-GORDON NONLINEAR}

Pada bagian ini, akan dikaji motivasi penurunan persamaan Klein-Gordon nonlinear yang didasarkan pada analogi yang sama seperti motivasi pada penurunan persamaan Schrodinger nonlinear. Melalui analogi tersebut, persamaan Klein-Gordon nonlinear dibangun dengan menambahkan suku potensial kuantum pada persamaan Klein-Gordon linear. Sebagai langkah awal, kita meninjau dahulu persamaan Klein-Gordon linear

$$
\frac{1}{c^{2}} \frac{\partial^{2} \Psi}{\partial t^{2}}-\nabla^{2} \Psi+\frac{m^{2} c^{2}}{\hbar^{2}} \Psi=0
$$

Pada persamaan di atas, m menyatakan massa diam partikel. Langkah selanjutnya, kita mengasumsikan bahwa fungsi gelombang $\Psi$ mempunyai solusi umum berbentuk

$$
\Psi(\vec{r}, t)=a(\vec{r}, t) e^{\frac{i}{\hbar} \varphi(\vec{r}, t)}
$$

dengan amplitudo $a(\vec{r}, t)$ dan fase $\varphi$ adalah fungsi ruang dan waktu. Apabila solusi umum pada Pers.(2) disubstitusikan pada Pers.(1), lalu bagian real dan imajiner dipisahkan maka akan didapat dua persamaan yang saling berhubungan satu sama lain

$$
\begin{array}{r}
-\frac{1}{c^{2}}\left(\frac{\partial \varphi}{\partial t}\right)+(\nabla \varphi)^{2}+\hbar^{2}\left(\frac{1}{c^{2} a} \frac{\partial^{2} a}{\partial t^{2}}-\frac{\nabla^{2} a}{a}\right) \\
+m^{2} c^{2}=0 \\
\nabla \bullet\left(a^{2} \nabla \varphi\right)=\frac{1}{c^{2}} \frac{\partial}{\partial t}\left(a^{2} \frac{\partial \varphi}{\partial t}\right)
\end{array}
$$

Melalui kedua persamaan di atas, kita belum mendapatkan hal yang penting. Namun demikian, apabila kita mengabaikan kontribusi kuantum pada Pers.(3), $\hbar \rightarrow 0$, dan mengganti $\varphi=S$, dengan $S$ merupakan aksi klasik, maka Pers.(3) akan tereduksi menjadi

$$
\frac{1}{c^{2}}\left(\frac{\partial S}{\partial t}\right)^{2}-(\nabla S)^{2}-m^{2} c^{2}=0
$$

Pers.(5) merupakan persamaan Hamilton-Jacobi klasik yang menggambarkan gerak partikel bebas. Di samping itu, suku yang mengandung konstanta Planck, $\hbar$

$$
Q=\hbar^{2}\left(\frac{1}{c^{2} a} \frac{\partial^{2} a}{\partial t^{2}}-\frac{\nabla^{2} a}{a}\right)
$$

disebut potensial kuantum. Melalui analogi pada mekanika klasik, dapat diturunkan beberapa besaran klasik lainnya melalui hubungan di bawah ini

$$
\begin{aligned}
-\frac{\partial \varphi}{\partial t} & =E=\gamma m c^{2} \\
\nabla \varphi & =\vec{p}=\gamma m \vec{v}
\end{aligned}
$$

dengan

$$
\gamma=\frac{1}{\sqrt{1-\frac{v^{2}}{c^{2}}}}
$$

adalah faktor kontraksi Lorentz. Di samping itu, didapat pula kecepatan partikel kuantum yang merupakan gradien dari fasenya

$$
\vec{v}=\frac{\nabla \varphi}{\gamma m}=\frac{\vec{p}}{\gamma m}
$$

Selanjutnya, apabila didefinisikan besaran $\rho=a^{2}$, kita mendapatkan persamaan kontinuitas yang menggambarkan gerak untuk awan partikel pada Pers.(4)

$$
\frac{\partial \rho}{\partial t}+\nabla \bullet(\rho \vec{v})=0
$$

dengan definisi rapat arus gelombang $\vec{J}=\rho \vec{v}$.

\section{PENURUNAN PERSAMAAN KLEIN-GORDON NONLINEAR}

Seperti yang telah dijelaskan pada bagian pendahuluan bahwa penurunan ini tidak menggunakan postulat Einstein dan de Broglie, namun menggunakan persamaan HamiltonJacobi dan kontinuitas. Melalui analogi yang sama, kita meninjau dahulu persamaan Hamilton-Jacobi untuk gerak partikel relativistik dan kontinuitas berikut ini

$$
\begin{gathered}
\frac{1}{c^{2}}\left(\frac{\partial \varphi}{\partial t}\right)^{2}-(\nabla \varphi)^{2}-m^{2} c^{2}=0 \\
\nabla \bullet\left(a^{2} \nabla \varphi\right)=\frac{1}{c^{2}} \frac{\partial}{\partial t}\left(a^{2} \frac{\partial}{\partial \varphi t}\right)
\end{gathered}
$$

Setelah melakukan aljabar matematika, maka kedua persamaan tersebut dapat dikombinasikan menjadi satu persamaan berikut

$$
\frac{1}{c^{2}} \frac{\partial^{2} \Psi}{\partial t^{2}}-\nabla^{2} \Psi+\frac{m^{2} c^{2}}{\hbar^{2}} \Psi-\frac{1}{c^{2} a} \frac{\partial^{2} a}{\partial t^{2}} \Psi+\frac{\nabla^{2} a}{a} \Psi=0 \text { (14) }
$$

dengan $\Psi$ adalah solusi umum yang telah didefinisikan pada Pers.(2). Pers.(14) merupakan persamaan Klein-Gordon nonlinear yang menggambarkan gerak partikel bebas relativistik.

Selanjutnya kita akan mengkaji kasus sederhana, yaitu solusi pertikel bebas untuk persamaan Klein-Gordon nonlinear. Untuk pencarian solusi ini digunakan metode yang sama seperti pada referensi [5]. Dalam hal ini solusi fasa, $\varphi$, didapatkan melalui penyelesaian solusi persamaan Hamilton-Jacobi pada Pers.(12) dengan menggunakan solusi ansatz yang mempunyai bentuk

$$
\varphi(\vec{r}, t)=\varphi_{1}(t)+\varphi_{2}(x)+\varphi_{3}(y)+\varphi_{4}(z)
$$

Setelah mensubstitusikan solusi ansatz Pers. (15) ke Pers. (12) akan didapatkan solusi untuk fase

$$
\varphi(\vec{r}, t)=-E t+\vec{p} \bullet \vec{r}
$$

dengan $\mathrm{E}$ dan $\vec{p}$ masing-masing adalah energi dan momentum linear untuk partikel relativistik. Selanjutnya, untuk mencari solusi amplitudo kita mensubstitusikan solusi Pers.(16) ke persamaan kontinuitas (13), didapat

$$
\frac{\partial a}{\partial t}+(\nabla a) \bullet \vec{v}=0
$$


Pers.(17) adalah persamaan differensial linear yang mempunyai solusi khusus amplitudo bernilai konstan $a(\vec{r}, t)=A$. Dengan demikian, solusi khusus persamaan Klein-Gordon nonlinear adalah gelombang bidang monokromatik dengan fungsi

$$
\Psi(\vec{r}, t)=A e^{\frac{i}{\hbar}(\vec{p} \bullet \vec{r}-E t)}
$$

\section{BENTUK UMUM PERSAMAAN KLEIN-GORDON NONLINEAR}

Bentuk perumusan persamaan Klein-Gordon nonlinear ini adalah menambahkan suku potensial eksternal pada Pers.(14). Potensial eksternal ini didapat melalui persamaan umum Hamilton-Jacobi untuk gerak partikel relativistik. Oleh sebab itu, kita menuliskan terlebih dahulu perluasan persamaan Hamilton-Jacobi berikut

$$
\frac{1}{c^{2}}\left(\frac{\partial \varphi}{\partial t}-V\right)^{2}-(\nabla \varphi)^{2}-m^{2} c^{2}=0
$$

dengan $\mathrm{V}$ merepresentasikan suku potensial eksternal. Langkah selanjutnya adalah dengan mengkombinasikan Persamaan kontinuitas (13) dengan Pers.(19).

Dengan menggunakan aljabar matematika, maka bentuk umum persamaan Klein-Gordon nonlinear mempunyai bentuk

$$
\begin{array}{r}
\frac{1}{c^{2}} \frac{\partial^{2} \Psi}{\partial t^{2}}-\nabla^{2} \Psi+\frac{m^{2} c^{2}}{\hbar^{2}} \Psi-\frac{1}{c^{2} a} \frac{\partial^{2} a}{\partial t^{2}} \Psi+ \\
\frac{\nabla^{2} a}{a} \Psi+\left(\frac{2}{\hbar^{2} c^{2}} \frac{\partial \varphi}{\partial t}-\frac{1}{c^{2} \hbar^{2}}\right) V \Psi=0
\end{array}
$$

dengan $\Psi$ adalah solusi umum yang telah didefinisikan pada Pers.(2). Penurunan Pers. (20) akan diuraikan pada lampiran.

\section{SIMPULAN}

Pada makalah ini telah dibahas mengenai motivasi dan penurunan persamaan Klein-Gordon nonlinear. Persamaan ini dirumuskan melalui persamaan Hamilton-Jacobi untuk gerak partikel relativistik dan kontinuitas. Persamaan HamiltonJacobi tersebut merupakan representasi bagian partikel yang membawa sebagian besar energi partikel kuantum sedangkan persamaan kontinuitas merepresentasikan bagian gelombang (awan partikel) yang membawa sebagian kecil energi partikel kuantum.

Solusi khusus untuk partikel bebas pada persamaan KleinGordon nonlinear tersebut mempunyai bentuk solusi gelombang bidang monokromatik. Seperti halnya pada persamaan Klein-Gordon linear, keberadaan energi negatif juga dapat diabaikan untuk partikel bebas pada persamaan Klein-Gordon nonlinear tersebut.

Persamaan Klein-Gordon umum yang memasukkan unsur potensial eksternal juga telah dapat dirumuskan. Perumusan umum ini didapat melalui persamaan umum Hamilton-Jacobi untuk partikel relativistik dengan memasukkan unsur potensial eksternal. Namun demikian, keberadaan energi negatif untuk kasus ini belum dapat disimpulkan secara pasti apakah dapat dihindari ataukah tidak. Hal ini terjadi mengingat perumusan Klein-Gordon nonlinear tersebut tidak menggunakan postulat Einstein dan de Broglie yang digunakan untuk menurunkan persamaan Klein-Gordon linear.

\section{Ucapan Terima Kasih}

Pada kesempatan ini, penulis mengucapkan terima kasih yang sebesar-besarnya kepada rekan-rekan dosen di jurusan fisika UNJ atas terwujudnya makalah ini.
[1] F. Guerra and M. Pusterla, Lett. Nuovo Cimento, 34, 351 (1982).

[2] Ph. Gueret and J. P. Vigier, Lett. Nuovo Cimento, 38, 125, (1983).

[3] L. Smolin, Phys. Lett., A 113, 408 (1986).

[4] J. P. Vigier, Phys. Lett., A 135, 99 (1989).

[5] T. B. Prayitno, Jurnal Fisika dan Aplikasinya (Spektra), Vol. IX, No. 2 Desember 2010.

[6] J. R. Croca, Towards a Nonlinear Quantum Physics (Singapore : World Scientific, 2003, pp. 65-82).

[7] L. de Broglie, An Introduction to the Study of Waves Mechanics (diterjemahkan oleh L. T. Flint, Paris : Methuen \& Co. Ltd, First published in 1930, pp. 26-31 dan 79-87).

[8] Walter Greiner, Classical Mechanics (System of Particles and Hamiltonian Dynamics) ( Springer-Verlag, 2003, pp. 386-409).

[9] W. Dittrich and M. Reuter, Classical and Quantum Dynamics (Berlin : Springer-Verlag, 1996, pp. 62-73).

[10] G. Kane, Modern Elementary Particle Physics (1st ed., Michigan : Westview Press, 1993, pp. 15-22).

[11] H. Goldstein, Classical Mechanics (3rd ed., Addison Wesley, New York 2000, pp. 430-439).
[12] L. H. Ryder, Quantum Field Theory (2nd ed., Cambridge University Press, New York, 1996, pp. 81-97). 
sehingga didapat

\section{LAMPIRAN}

Penurunan Pers.(20) diuraikan sebagai berikut. Pertama, tuliskan kembali persamaan Hamilton-Jacobi dan persamaan kontinuitas yang terdapat pada Pers.(13) dan (19):

$$
\begin{array}{r}
\nabla \bullet\left(a^{2} \nabla \varphi\right)=\frac{1}{c^{2}} \frac{\partial}{\partial t}\left(a^{2} \frac{\partial \varphi}{\partial t}\right) \\
\frac{1}{c^{2}}\left(\frac{\partial \varphi}{\partial t}-V\right)^{2}-(\nabla \varphi)^{2}-m^{2} c^{2}=0
\end{array}
$$

Kemudian, jabarkan Pers.(21), lalu kalikan dengan $i \hbar$ pada kedua ruasnya, sehingga didapat

$$
\begin{array}{r}
2 i \hbar a(\nabla a) \bullet(\nabla \varphi)+i \hbar a^{2} \nabla^{2} \varphi= \\
2 \frac{i \hbar}{c^{2}} a \frac{\partial a}{\partial t} \frac{\partial \varphi}{\partial t}+i \hbar \frac{a^{2}}{c^{2}} \frac{\partial^{2} \varphi}{\partial t^{2}}
\end{array}
$$

Setelah itu, jabarkan pula Pers.(22), kalikan dengan a pada kedua ruasnya, lalu manipulasikan suku kirinya dengan menambahkan suku

$$
\left(\frac{\hbar^{2}}{c^{2}} \frac{\partial^{2} a}{\partial t^{2}}-\frac{\hbar^{2}}{c^{2}} \frac{\partial^{2} a}{\partial t^{2}}\right)
$$

dan

$$
\left(\hbar^{2} \nabla^{2} a-\hbar^{2} \nabla^{2} a\right)
$$

$$
\begin{gathered}
\frac{\hbar^{2}}{c^{2}} \frac{\partial^{2} a}{\partial t^{2}}-\frac{\hbar^{2}}{c^{2}} \frac{\partial^{2} a}{\partial t^{2}}+\hbar^{2} \nabla^{2} a-\hbar^{2} \nabla^{2} a+\frac{1}{c^{2}}\left(\frac{\partial \varphi}{\partial t}\right)^{2} a-(24) \\
\frac{2 V}{c^{2}} \frac{\partial \varphi}{\partial t} a+\frac{V^{2}}{c^{2}} a-(\nabla \varphi)^{2} a-m^{2} c^{2} a=0
\end{gathered}
$$

Lalu kita jumlahkan Pers.(23) dan (24), kalikan hasil akhirnya dengan $e^{\frac{i}{\hbar} \varphi}$, dan setelah menggunakan definisi fungsi gelombang umum yang terdapat pada Pers.(2)

$$
\Psi(\vec{r}, t)=a(\vec{r}, t) e^{\frac{i}{\hbar} \varphi(\vec{r}, t)}
$$

maka didapatkan Pers.(20)

$$
\begin{array}{r}
\frac{1}{c^{2}} \frac{\partial^{2} \Psi}{\partial t^{2}}-\nabla^{2} \Psi+\frac{m^{2} c^{2}}{\hbar^{2}} \Psi-\frac{1}{c^{2} a} \frac{\partial^{2} a}{\partial t^{2}} \Psi+ \\
\frac{\nabla^{2} a}{a} \Psi+\left(\frac{2}{\hbar^{2} c^{2}} \frac{\partial \varphi}{\partial t}-\frac{1}{c^{2} \hbar^{2}}\right) V \Psi=0
\end{array}
$$

Apabila pada Pers.(26) diambil kasus partikel bebas $(\mathrm{V}=0)$, maka persamaan tersebut akan tereduksi menjadi Pers.(14). 